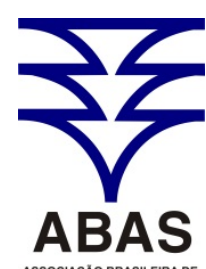

ASSOCIACAOB BRASLLERADE
AGUAS SUBTERRANEAS www.abas.org

\title{
DIAGNÓSTICO HIDROGEOLÓGICO DA REGIÃO DE ARAMARI E OURIÇANGAS-BAHIA
}

\author{
HYDROGEOLOGICAL ASSESSMENT OF THE REGION OF ARAMARI \\ AND OURIÇANGAS-BAHIA
}

\author{
Sérgio Nascimento ${ }^{1}$; Cora Alves Sales ${ }^{2}$; Ramille Pinto Raimundo ${ }^{3}$
}

Artigo recebido em: 21/10/2014 e aceito para publicação em: 23/03/2015.

DOI: http://dx.doi.org/10.14295/ras.v29i2.27975

\begin{abstract}
Hydrogeological and hydrochemical aspects of groundwater in the municipalities of Aramari and Ouriçangas were studied in order to evaluate the potential for water production wells in the region, relating them to the main sedimentary formations present in the area, as well as information on its type and quality. The hydrogeological data enabled set the NE-SW direction of groundwater flow. The statistical thresholds for the flow rates were established, determining the best wells in the area and its connection with the formations Barreiras, Marizal, São Sebastião, Candeias / Sergi and the Group Ilhas undivided. Regarding quality, emphasis has been placed mainly the presence of barium, barite mineral component, which occurs as cement in sandstone lenses of Marizal Training percolated by groundwater in the region, and that can cause serious harm to human health. The triangular diagram of Piper was used to determine the classification of these waters, revealing essentially of sodium chlorinated nature in eleven wells studied. Waters are generally of good quality, with the exception of some high salinity and have influences of training Candeias / Sergi. Nitrate, potassium, barium, lead and aluminum exceeded the maximum acceptable value for human consumption in some samples, the first two being probably originated from anthropogenic contamination as barium, lead and aluminum would be associated with geogenic contamination.
\end{abstract}

Keywords: Hydrogeology. Flow. Barium. Aramari. Ouriçangas.

Resumo: Aspectos hidrogeológicos e hidroquímicos da água subterrânea nos municípios de Aramarí e Ouriçangas foram estudados, com o objetivo de avaliar o potencial de produção de água de poços tubulares da região, relacionando-os com as principais formações sedimentares presentes na área, além de obter informações sobre a sua tipologia e qualidade. Os dados hidrogeológicos possibilitaram definir a direção NE-SW do fluxo de água subterrânea. Foram estabelecidos os limiares estatísticos das vazões, determinando os melhores poços da área e sua ligação com as formações Barreiras, Marizal, São Sebastião, Candeias/Sergi e o Grupo Ilhas Indiviso. Em relação à qualidade, deu-se ênfase principalmente a presença de bário, componente do mineral barita, que ocorre como cimento em lentes de arenitos da Formação Marizal percolados pela água subterrânea na região, e que pode causar graves danos à saúde humana. Foi utilizado o diagrama triangular de Piper para estabelecer a classificação dessas águas, revelando-se essencialmente de natureza cloretada sódica em onze poços estudados. São em geral águas de boa qualidade, com exceção de algumas com alta salinidade e que têm influências da formação Candeias/Sergi. Nitrato, potássio, bário, chumbo e alumínio excederam o valor máximo aceitável para consumo humano em algumas amostras, sendo os dois primeiros oriundos provavelmente de contaminação antrópica enquanto o bário, chumbo e alumínio estariam associados a contaminação geogênica.

Palavras-chave: Hidrogeologia. Vazão. Bário. Aramarí. Ouriçangas.

\section{INTRODUÇÃO}

O Sistema Aquífero Marizal/São Sebastião representa uma das principais unidades hidrogeológicas, sendo muito importante no Estado da Bahia, e conta com grandes volumes armazenados de água doce e nor- malmente potável, que abastecem parte da população da região do Recôncavo Norte, notadamente os grandes municípios como Alagoinhas e Camaçari. Com esse trabalho pretendeu-se definir o potencial produtivo

\footnotetext{
${ }^{1}$ Universidade Federal da Bahia (sergiomn@ufba.br)

${ }^{2}$ Universidade Federal da Bahia (cora.sales.silva@gmail.com)

${ }^{3}$ Universidade Federal da Bahia (ramilled@gmail.com)
} 
dos poços tubulares e seus aquíferos, além da potenciometria e fluxo subterrâneo na região dos municípios de Aramarí e Ouriçangas. Esses dois municípios têm poucas indústrias instaladas e, segundo o Serviço Geológico do Brasil - (CPRM, 2005), a água subterrânea é principalmente utilizada para consumo humano (cerca de $70 \%$ do total produzido), enquanto a agricultura consome $15 \%$ e o comércio/indústria os outros $15 \%$. Como o maior consumo é humano, procurou-se definir aspectos hidroquímicos importantes, tais como, os tipos de água subterrânea. Essas foram classificadas através do diagrama triangular de Piper utilizando-se valores dos cátions e ânions dos elementos maiores em unidades miliequivalentes através do programa Qualigraf (FUNCEME, 2009). Para estabelecer a qualidade da água utilizou-se o padrão proposto pela Portaria 2914/2011 do Ministério da Saúde. Quanto a qualidade da água destacou-se a presença bário, devido à existência de barita como cimento nos arenitos de origem fluvial que ocorrem na Formação Marizal (SOUZA, 1984). Essa lente de arenito enriquecido em barita já foi lavrado a partir de depósitos economicamente viáveis, com reservas segundo a Petromisa, de aproximadamente 200.000 toneladas (CBPM, 1984).

Como a água subterrânea é muito utilizada para consumo humano foi necessário calcular o índice de saturação e as formas de especiação do bário. A água subterrânea, em contato com a barita, forma um sistema geoquímico que consiste de uma fase sólida (barita) e uma fase líquida (água). O processo de dissolução se prolonga até atingir o equilíbrio entre a fase sólida e a líquida. Quando a solução alcança um ponto de saturação acima do equilíbrio químico, ocorre a precipitação parcial ou total desse mineral; caso contrário não ocorre a precipitação química de qualquer espécie de bário na região. Isso é importante porque a depender da quantidade de $\mathrm{Ba}^{++}$dissolvido na água, alguns danos pode ser verificado no sistema nervoso, sistema cardiovascular, além de provocar tremores, fraquezas, ansiedade, entre outras manifesta- ções. Quando em excesso no organismo, por ser vasoconstritor, pode causar hipertensão arterial, fadiga e doenças cardiovasculares, grande causa de derrames e acidentes vasculares (FIUME, 2010). Em 1996 a Organização Mundial de Saúde e em 2011 o Ministério da Saúde do Brasil admitiram em água potável um valor limite de referência de 0,7 mg. $L^{-1}$ para o bário.

\section{OBJETIVO}

Este trabalho teve como objetivo principal de avaliar a água subterrânea nos municípios de Aramarí e Ouriçangas-Bahia, e com seguintes objetivos específicos: I) avaliar as vazões dos poços tubulares e suas relações com os diversos aqüíferos da região; II) definir a superfície potenciométrica e as direções de fluxo subterrâneo; III) avaliar comportamento dessa superfície ao longo das últimas quatro décadas; IV) verificar a qualidade da água comparando com os valores encontrados na Portaria 2914/2011 do Ministério da Saúde para enquadramento e consumo humano; V) classificar as águas através do diagrama triangular de Piper; VI) analisar a existência de contaminação por elementos traço, principalmente o bário; VII) verificar o grau de salinização da água através das medidas de condutividade elétrica e sólidos totais dissolvidos; VIII) estabelecer a associação e correlação entre os diversos parâmetros analisados na água.

\section{3 ÁREA DE ESTUDO}

Os municípios de Aramarí e Ouriçangas estão inseridos na Bacia Sedimentar do Recôncavo Norte, entre as coordenadas: $11^{\circ}$ 55'51', e $12^{\circ}$ 15'23', de latitude sul e $38^{\circ} 15^{\prime} 00^{\prime \prime}$ e $38^{\circ} 35^{\prime} 00^{\prime \prime}$ de longitude oeste. Estão localizados a aproximadamente 127 $\mathrm{km}$ ao norte da capital baiana, e limitando-se com os municípios de Inhambupe ao norte, Alagoinhas e Catu ao sul, Entre Rios a leste e Teodoro Sampaio a oeste. A figura 1 ilustra o acesso a partir de Salvador. 


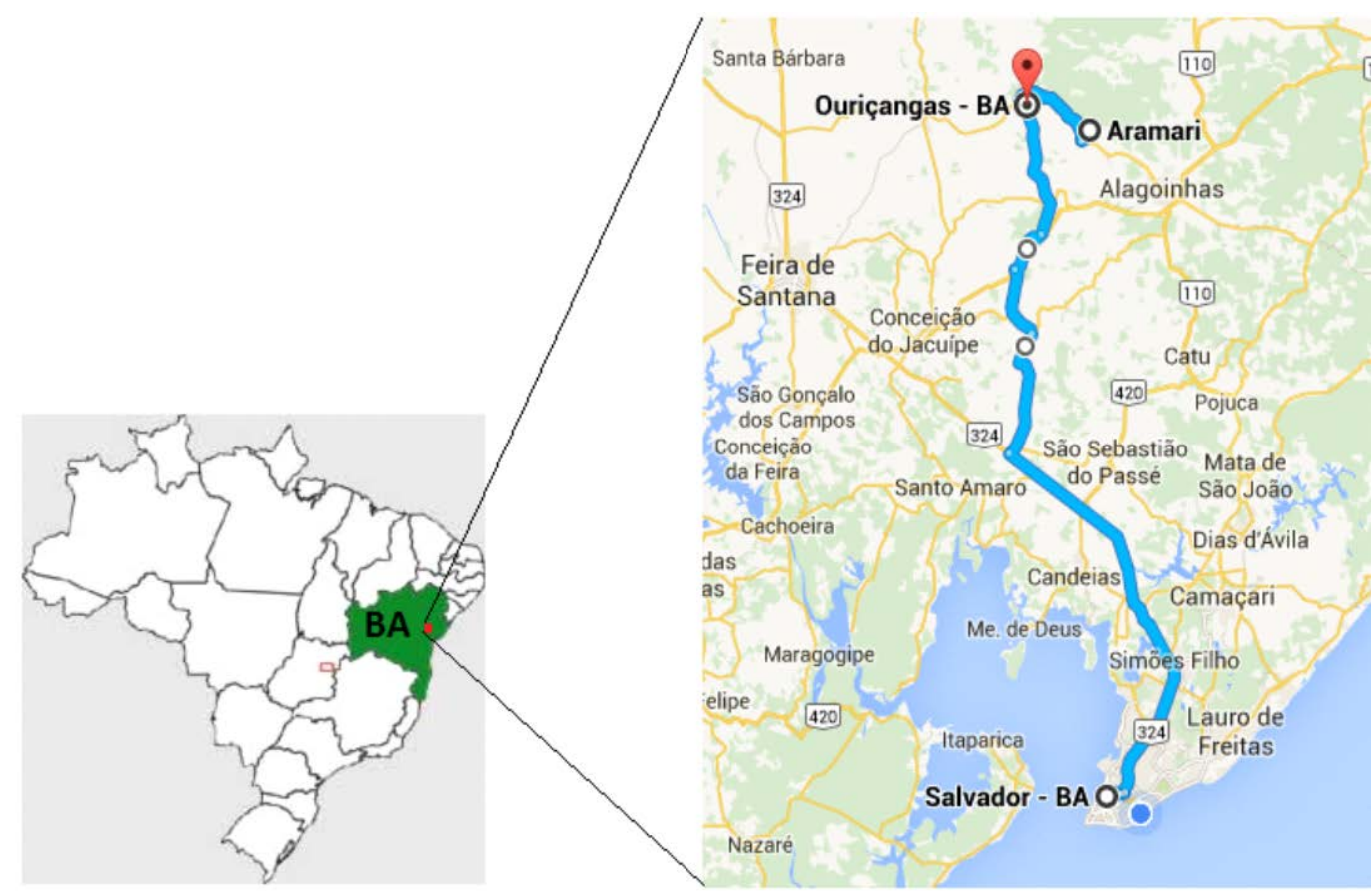

Figura 1 - Localização e acesso à área

Figure 1 - Location and access to the area

Fonte: Google Maps (2014)

Geologia - A região apresenta uma variedade de rochas sedimentares, que englobam desde os sedimentos associados à sequência pré-rift da bacia sedimentar do Recôncavo, até os sedimentos Terciários, representados pela Formação Barreiras (Figura 2).

A Formação Barreiras constitui uma cobertura sedimentar terrígena continental, de idade pliocênica, depositada por sistemas fluviais entrelaçados, associados a leques aluviais. É composta por uma sequência de sedimentos detríticos, siliciclásticos de origem fluvial e marinha (ARAI, 2006 apud NUNES, 2011), pouco ou não consolidadas, mal selecionadas e de cores variadas (VILAS BOAS, 1996; VILAS BOAS; SAMPAIO; PEREIRA, 2001 apud NUNES, 2011).

Sua base é composta por conglomerado estratificado onde predominam grãos de quartzo leitoso, fragmentos alterados de rochas metamórficas, arenito e seixos de argila, envoltos em uma matriz arenosa de composição complexa e mal selecionados. Os arenitos apresentam a mesma composição da ma- triz dos conglomerados, com cores que variam de vermelho a violeta, branca e amarela, e ocorrem na maioria dos casos, formando estratificações plano-paralelas. A porção argilosa ocorre em menor quantidade e se resume a finas camadas de siltito de cores variadas (PROJETO RADAMBRASIL, 1981).

A Formação Marizal encontra-se essencialmente nas porções nordeste e centro leste da área de estudo. Destaca-se na paisagem pelo relevo topográfico em forma de tabuleiro, a maioria dissecados, que inclui localmente topos de material da Formação Barreiras, ambas sobrepostas à Formação São Sebastião (PROJETO RADAMBRASIL, 1981). É constituída por sedimentos depositados em ambiente de leques aluviais e sistemas fluviais entrelaçados (LIMA, 1991). Está representada basicamente por arenitos de granulação média a grossa em parte conglomerático, de colorações esbranquiçada, alaranjada, avermelhada, com laminações cruzadas tabulares de porte médio (SOUZA, 1984; CBPM, 1984). 


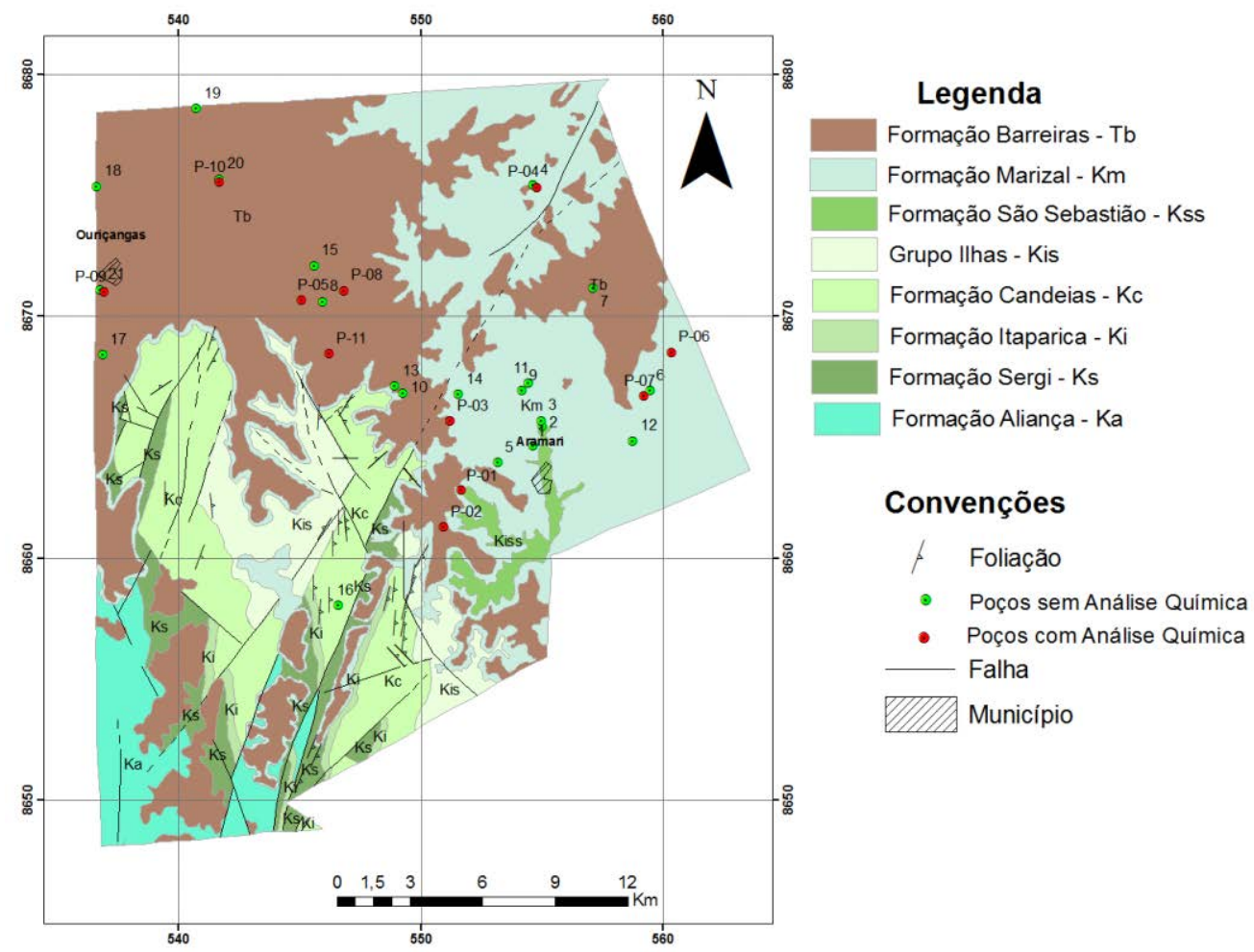

Figura 2 - Mapa geológico da área de estudo Figure 2 - Geological map of the study area

Em sua porção basal são encontrados orto e paraconglomerados de matriz arenítica, com seixos predominantemente granulíticos e subordinadamente de quartzitos e quartzo de veio, mal selecionados e arredondados. Os arenitos são cauliníticos e maciços ou com estratificação cruzada, e apresentam coloração que varia de cinza-esbranquiçado a amarelo avermelhado, variam de finos a grosseiros, mal selecionados, subangulares a subarredondados, quartzosos e feldspáticos (FONSECA, 2004).

Os folhelhos que ocorrem na Formação Marizal são siltosos, pouco calcíferos, às vezes apresentando lâminas de gipsita e barita ou camadas de sílex bandadas. Os siltitos são micáceos, argilosos, raramente ferruginosos e calcíferos. No topo da formação ocorrem fácies lamíticas de argila caulinítica clara ou de argilas illíticas avermelhadas ou de cores variadas (CBPM, 2001). A barita, na região de Ouriçangas, ocorre como cimento no arenito mineralizado (SOUZA, 1984). Esse mineral ocorre como massa espática ocupando espaços intergranulares, engloban- do diversos grãos detríticos, formada durante o processo diagenético (SOUZA, 1984). Segundo este autor a barita se formou na época da litificação desse arenito como consequência da percolação de soluções ricas em bário: a barita foi lavrada economicamente até pouco tempo, numa área a sudeste de Ouriçangas.

A Formação São Sebastião aflora com uma pequena expressão, nas proximidades do município de Aramarí. Geralmente constituem serras arredondadas ou morrotes ondulados, limitando-se em sua parte inferior com os sedimentos do Grupo Ilhas de maneira transicional e, em sua porção superior com os sedimentos da Formação Marizal, de maneira discordante erosiva/angular (COSTA et al., 2007). A Formação São Sebastião se divide em três membros: inferior, médio e superior, batizados respectivamente de Paciência, Passagem dos Teixeiras e Rio Joanes. O membro Paciência é composto essencialmente por dois corpos de arenito separados por uma seção de siltitos e folhelhos. O arenito da base, conhecido com Arenito Bebedouro, 
apresenta granulometria grosseira e grãos arredondados e subarredondados. Possui coloração cinza a branco e uma gradação de tamanhos é perceptível (PROJETO RADAMBRASIL, 1981). Em sua porção superior, ocorre intercalado com folhelhos sílticos violeta e cinza. O arenito do topo apresenta as mesmas características que o da base, porém é mais espesso e com maior número de intercalações de siltitos verde-cinza e vermelhos.

O membro Passagem dos Teixeiras é composto por arenitos rosados, cinza e amarelos, siltitos e folhelhos vermelhos e um folhelho verde-cobre contendo lâminas e cristais de barita. Os arenitos são quartzosos, grosseiros, mal selecionados, maciços e interestratificados com folhelhos e siltitos verdes ou cinza e calcários nodulares impuros.

No membro Rio Joanes, predominam os arenitos amarelos, róseos, vermelho brilhante, quartzosos, mal selecionados e texturalmente impuros. Possuem grande espessura, são maciços e ás vezes com estratificação cruzada e intercalações de argilas sílticas, folhelhos e siltitos.

As características litológicas e estruturais dos arenitos da Formação São Sebastião indicam uma sedimentação inicialmente fluvial, com posterior retrabalhamento por vento, onde a base representa um sistema fluvial de alta energia e o topo um ambiente desértico tipicamente eólico (COSTA et al., 2007).

As rochas representantes do Grupo Ilhas ocorrem na porção central e centro-sul da área de estudo, constituindo suaves ondulações sem muita expressão topográfica. Os litotipos e estruturas primárias encontradas nos sedimentos do Grupo Ilhas sugerem uma deposição em planície e frente deltaica (COSTA et al., 2007). O contato com a Formação Candeias é do tipo gradacional, enquanto o contato com a Formação São Sebastião, sobrejacente, é marcado por uma discordância angular. Foi encontrado até 2.360 ppm de chumbo em fácies argilosas do Grupo Ilhas (SOUZA, 1984).
A formação Candeias é constituída por uma sequência dominante de folhelhos e siltitos argilosos de coloração marrom a cinza esverdeada, intercalada por arenitos grosseiros a finos, contendo níveis de calcarenitos e calcissiltitos silicificados, fossilíferos e, localmente, níveis de gipsita. São observados também arenitos médios a finos, localmente grosseiros, de coloração avermelhada a creme amarelados, intercalados por horizontes de siltitos e argilitos, contendo lâminas e nódulos ferruginosos concordantes com o acamamento (COSTA et al., 2007).

A Formação Sergi é composta por arenitos com granulometria fina a conglomerática, coloração cinza-esverdeada e avermelhada e estratificação cruzada acanalada, além de intercalações de folhelhos vermelhos a cinza-esverdeados. No topo, ocorrem conglomerados finos a médios e arenitos com seixos esparsos, onde se destacam os fenoclastos de sílex (PROJETO RADAMBRASIL, 1981).

Clima - O clima da região é classificado segundo Thornthwaite (SEI, 1998) como Seco Sub-Úmido, com índice hídrico de 20 a $0 \%$ e excedente hídrico entre 50 e 300 $\mathrm{mm}$, sendo o outono e o inverno as estações definidas pelo regime pluviométrico (Figura 3 ). As temperaturas médias variam de $21,0^{\circ} \mathrm{C}$ a $25,7^{\circ} \mathrm{C}$, na estação meteorológica Alagoinhas, que é a mais próxima aos municípios de Aramarí e Ouriçangas.

As Normais Climatológicas no período de 1961 a 1990 foram publicadas pelo Instituto Nacional de Meteorologia-INMET (1992) e modelados pela Empresa Brasileira de Pesquisa Agropecuária-EMBRAPA. As precipitações médias mensais para a região variam de 60 a $175 \mathrm{~mm}$, com períodos mais chuvosos entre março e agosto e períodos de estiagem de setembro a fevereiro. O gráfico do balanço hídrico (Figura 3) mostra a relação entre a precipitação e evapotranspiração (ETR) e evapotranspiração potencial (ETP), a qual confirma o excedente hídrico. 


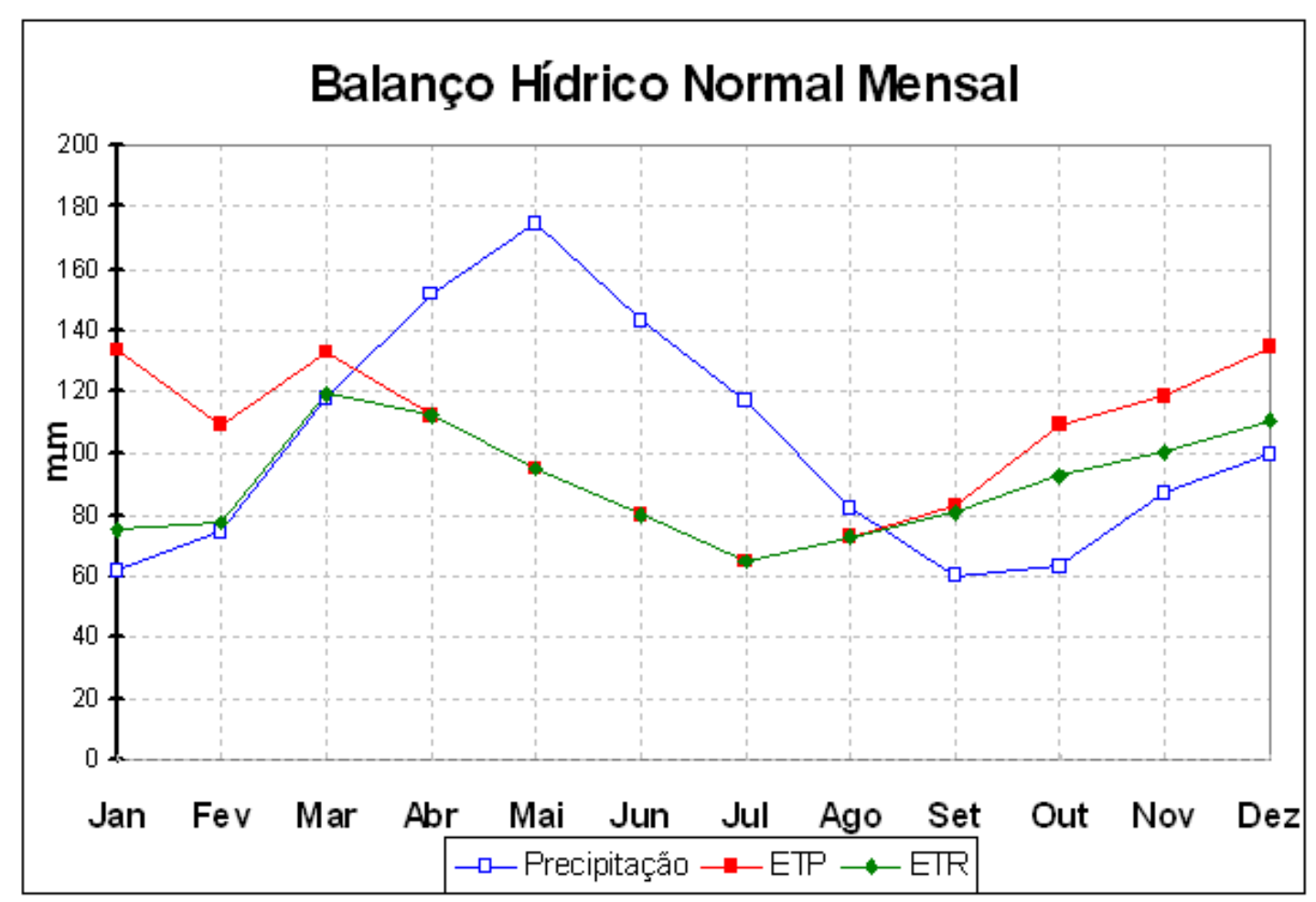

Figura 3- Balanço hídrico: precipitação, evapotranspiração (ETR) e evapotranspiração potencial (ETP) no período de 1961 - 1990

Figure 3- Water balance between precipitation, evapotranspiration (ETR) and potential evapotranspiration (ETP) in the period of 1961-1990

Hidrogeologia - A região encontra-se sob a influência do Oceano Atlântico, que interfere nas características térmicas, no regime e na intensidade das chuvas, sendo marítimos os ventos que trazem os sistemas meteorológicos portadores de chuvas para a região. A forma de captação principal de água subterrânea nos municípios de Aramarí e Ouriçangas é através dos poços tubulares rasos ou profundos, utilizados em pequenos e grandes abastecimentos. Outras formas de captação são as fontes naturais e cisternas, de uso comum nas duas sedes municipais.

A região tem um potencial hidrogeológico que se caracteriza como um dos melhores do Estado da Bahia, principalmente o sistema aquífero constituído pelas Formações Marizal e São Sebastião. Essa Formação apresenta na região do Recôncavo Norte, reserva permanente de água subterrânea (Rp) de 29,2 x $10^{8} \mathrm{~m}^{3}$ e reserva explorável (Re) de 147,4 x $10^{7} \mathrm{~m}^{3}$ (IBGE, 1999). A Formação Marizal possui elevado potencial de disponibilidade hídrica subterrânea, associado principalmente à sua sequência conglomerática basal. Essa Formação apresenta na região do Recôncavo Norte reservas permanente (Rp) de $1,05 \times 10^{8} \mathrm{~m}^{3}$ e explorável (Re) de 2,60 x $10^{7} \mathrm{~m}^{3}$ (IBGE, 1999). Embora a sua potencialidade como reservatório seja menor que a da Formação São Sebastião, a maior parte da recarga é controlada pelas Formações Barreiras e Marizal. Em alguns locais, a Formação Marizal repousa diretamente sobre os arenitos da Formação São Sebastião, permitindo, através desse contato a transferência vertical de água entre as duas formações. Quando a sobreposição está sobre os folhelhos da Formação São Sebastião, ocorrem fontes e surgências naturais, que funcionam como exutórios do aquífero (IBGE, 1999).

\section{METODOLOGIA}

O levantamento dos dados iniciou-se pela revisão bibliográfica em dissertações, teses, artigos e anais de congressos, e por consultas aos bancos de dados da Companhia de Engenharia Ambiental da Bahia (CERB), no Sistema de Informações de Águas Subterrâneas (SIAGAS) do Serviço Geológico do Brasil (CPRM), e no projeto Aramarí da Compa- 
nhia Baiana de Pesquisa Mineral (CBPM): Também foram consultadas as Resoluções e Portarias do Ministério da Saúde e do Conselho Nacional de Meio Ambiente - CONAMA.

A consulta aos bancos de dados resultou em informações sobre 21 poços tubulares (Figura 2), sua localização, coordenadas geográficas, litologias, data de perfuração, nível estático, dinâmico e dados sobre a salinidade da água. Selecionou-se 11 poços para a amostragem de água subterrânea no verão de 2011 (Figura 2). O critério principal para a escolha desses poços foi a existência de informações geológicas, hidrogeológicas e químicas existentes em fichas padronizadas no banco de dados do SIAGAS/CPRM, além de estarem estrategicamente bem localizados e de fácil acesso na área.

A amostragem da água subterrânea foi realizada após ser “expurgada” e bombeada por cerca de 20 minutos, tempo suficiente para renovar a coluna de água no poço. Foram utilizados recipientes de polietileno com tampa vedante, cedido pelos laboratórios que realizaram as análises e preenchida uma ficha cadastral com dados observados em campo. No ato da coleta da água e com o auxilio de uma seringa e filtro de acetato de celulose, marca Sartorius, com poros de $0,45 \mu \mathrm{m}$, procedeu-se a filtragem da água para eliminar partículas em suspensão. Os recipientes utilizados na coleta de água para a análise dos metais continham no seu interior algumas gotas de $\mathrm{HCl}$ para acidular e preservar a água coletada, sendo em seguida acondicionados em isopor com gelo.

No campo foram realizadas medidas com equipamento multiparamétrico marca Eureka - modelo Manta2. Foram medidos a temperatura, o oxigênio dissolvido (OD), a condutividade elétrica (CE), a salinidade, o pH, a amônia e o nitrato. As análises dos íons principais $\left(\mathrm{Ca}^{2+}, \mathrm{Mg}^{2+}, \mathrm{Na}^{+}, \mathrm{K}^{+}, \mathrm{Cl}^{-}, \mathrm{SO}_{4}{ }^{2-}\right.$, $\mathrm{HCO}_{3}{ }^{-}$) e elementos traços (Ferro, Cobre, Zinco, Manganês, Bário e chumbo), foram realizadas nos laboratórios do Instituto de Geociências/UFBA e no Senai/Cetind. Foram utilizadas técnicas, procedimentos e metodologias apropriadas para cada tipo de análise, de acordo com os manuais do Standard Methods of Water and Wasterwater $19^{\text {th }}$ e $20^{\text {th }}$ Editions de
1992 e 1998 e da Varian Indústria e Comércio Ltda.

Com as informações obtidas foram elaboradas duas planilhas Excel: uma com os parâmetros hidrogeológicos dos 21 poços pesquisados nos bancos de dados da CERB e do SIAGAS/CPRM e a outra com as variáveis hidrogeoquímicas dos 11 poços amostrados no campo. Posteriormente essas informações foram tratadas estatisticamente através dos softwares Excel (2007) e Statistica 7.0. Com o Qualigraf (FUNCEME, 2009) foram estabelecidos os tipos e a classificação das águas subterrâneas através do diagrama triangular de Piper e, com o Phrreqc 2.0 (Parkhurst e Apello, 1999) determinou-se os índices de saturação e a especiação do bário. A confecção do mapa potenciométrico da área foi realizado através do software Surfer 9.0, utilizando-se os dados de cota topográfica do poço e o nível estático do aquífero em cada um dos 21 poços pesquisados nos bancos de dados. Esses valores foram interpolados com krigagem ordinária. Para estabelecer a qualidade das águas foi utilizada a portaria 2914/2011 do Ministério da Saúde

\section{RESULTADOS E DISCUSSÃO}

Para definir as características hidrogeológicas básicas do sistema aquífero, foram utilizadas as informações da base de dados dos 21 poços tubulares perfurados e desenvolvidos em diferentes épocas por diversas empresas de perfuração, distribuídos aleatoriamente por toda área de trabalho. Estes poços têm profundidades que variam de 40 a 184 metros no município de Aramarí e de 30 a 257 metros, em Ouriçangas.

Considerando o terceiro quartil de $75 \%$ (Tabela 1), os poços que apresentam vazões acima de $34,4 \mathrm{~m}^{3} / \mathrm{h}$ podem ser considerados como os melhores da região. O poço 4 (Figura 2) situado na localidade de Subaúma Mirim (município de Aramarí) é utilizado para o abastecimento urbano; tem vazão de 34,41 $\mathrm{m}^{3} / \mathrm{h}$, e $61 \mathrm{~m}$ de profundidade (SIAGAS, 2013).

O posicionamento dos filtros indica entrada d'água entre $30 \mathrm{~m}$ e $60 \mathrm{~m}$ de profundidade, estando localizada nos arenitos de granula- 
ção média a grossa da Formação São Sebastião (SIAGAS, 2013).

Vazões acima de $104,0 \mathrm{~m}^{3} / \mathrm{h}$ (percentil 90\%), caso existam na região, já que não foi constatado em nenhum dos poços estudados, podem ser considerados estatisticamente excepcionais, ou seja, são vazões extremas. Vazões específicas acima de $2,0 \mathrm{~m}^{3} / \mathrm{h} / \mathrm{m}$ é considerada como muito boa para a região, e acima de $12 \mathrm{~m}^{3} / \mathrm{h} / \mathrm{m}$, caso existam na região, já que não foi constatada em nenhum dos poços estudados, são estatisticamente excepcionais (Tabela 1).

O poço 7, situado na localidade de Subaúma (município de Aramarí), é utilizado no abastecimento urbano (Figura 2.). Tem vazão de $34,0 \mathrm{~m}^{3} / \mathrm{h}$ (mesma vazão do poço 4 segundo dados do SIAGAS/CPRM) e 91m de profundidade (SIAGAS, 2013). A água é extraída abaixo de 60m de profundidade e está armazenada nas areias de granulação média da Formação Barreiras (SIAGAS, 2013).

O poço 15, na localidade de Ouriçanguinhas (município de Aramarí), tem profundidade de $50 \mathrm{~m}$ e sua vazão é de $39,6 \mathrm{~m}^{3} / \mathrm{h}$ após estabilização. A água é extraída entre as profundidades de $10 \mathrm{~m}$ e $32 \mathrm{~m}$ e está armazenada nas areias inconsolidadas da Formação Marizal (SIAGAS, 2013); tem uma elevada vazão específica de $12,77 \mathrm{~m}^{3} / \mathrm{h} / \mathrm{m}$ (SIAGAS, 2013). O poço 18, na localidade de Curimungo/Olho D’água (município de Ouriçangas), serve para o abastecimento rural e urbano. Tem vazão de $46,58 \mathrm{~m}^{3} / \mathrm{h}$ e profundidade 257,3 metros. O nível produtor de água está entre as profundidades de $140 \mathrm{~m}$ a $160 \mathrm{~m}, 190 \mathrm{~m}$ e $200 \mathrm{~m}$ e $220 \mathrm{~m}$ a $245 \mathrm{~m}$ e a rocha armazenadora são os arenitos argilosos do Grupo Ilhas (SIAGAS, 013).

Tabela 1 - Estatística de parâmetros hidrogeológicos básicos

Table 1 - Summary statistics - basic hydrogeological parameters

\begin{tabular}{|c|c|c|c|c|c|c|c|c|c|c|c|c|}
\hline Variável & $\mathrm{N}$ & $\begin{array}{c}\text { Média } \\
\text { Aritmética }\end{array}$ & $\begin{array}{l}\text { I.C. - } \\
95 \%\end{array}$ & $\begin{array}{l}\text { I.C. } \\
+95 \%\end{array}$ & Mediana & $\begin{array}{c}\text { Valor } \\
\text { Mínimo }\end{array}$ & $\begin{array}{c}\text { Valor } \\
\text { Máximo }\end{array}$ & $\begin{array}{c}\text { Quartil } \\
25 \%\end{array}$ & $\begin{array}{c}\text { Quartil } \\
75 \%\end{array}$ & $\begin{array}{c}\text { Percentil } \\
10 \%\end{array}$ & $\begin{array}{c}\text { Percentil } \\
90 \%\end{array}$ & $\mathrm{~A}_{3}$ \\
\hline Prof & 21 & 93,2 & 67,6 & 118,7 & 81,0 & 30,0 & 257,3 & 59,8 & 98,0 & 40,0 & 176,0 & 1,58 \\
\hline Cota & 21 & 248,9 & 228,2 & 269,7 & 231,0 & 199,0 & 344,0 & 216,0 & 255,0 & 206,0 & 326,0 & 1,01 \\
\hline Cota-NE & 21 & 234,3 & 217,4 & 251,1 & 224,3 & 187,1 & 330,0 & 206,1 & 248,2 & 199,0 & 261,3 & 1,30 \\
\hline $\mathrm{NE}$ & 21 & 14,7 & 4,7 & 24,6 & 6,9 & 0,0 & 82,7 & 2,9 & 13,9 & 0,5 & 37,0 & 2,40 \\
\hline ND & 21 & 67,0 & 50,7 & 89,3 & 58,0 & 10,1 & 119,7 & 39,6 & 104,0 & 26,8 & 107,0 & 0,10 \\
\hline ND-NE & 21 & 34,7 & 22,4 & 46,9 & 32,5 & 1,5 & 116,9 & 115,0 & 43,0 & 5,1 & 65,9 & 1,39 \\
\hline Vae & 21 & 35,0 & 16,7 & 53,4 & 13,9 & 0,4 & 46,9 & 7,5 & 34,4 & 6,5 & 104,0 & 1,18 \\
\hline Vesp & 21 & 7,2 & $-2,9$ & 17,4 & 0,5 & 0,1 & 5,1 & 0,2 & 2,0 & 0,1 & 12,8 & 4,19 \\
\hline
\end{tabular}

Parâmetros: Prof. $(\mathrm{m})$ = profundidade; NE (m) = Nível Estático; ND (m) = Nível Dinâmico; ND-NE (m) = Rebaixamento; Vae $\left(\mathrm{m}^{3} / \mathrm{h}\right)$ = vazão; Vesp = vazão específica; $\mathrm{A}_{3}=$ assimetria

\subsection{A superfície potenciométrica da região}

Os dados potenciométricos oriundo dos 21 poços tubulares avaliados foram medidos ao longo das últimas quatro décadas. No modelamento das linhas equipotenciais utilizaram-se os valores da cota topográfica dos po- ços (Z) determinadas a partir de informações do Modelo Digital do Terreno e do nível estático da água subterrânea (NE). O resultado mostrou que a direção geral de fluxo subterrâneo na área tem o sentido aproximado NE-SW (Figura 4): 


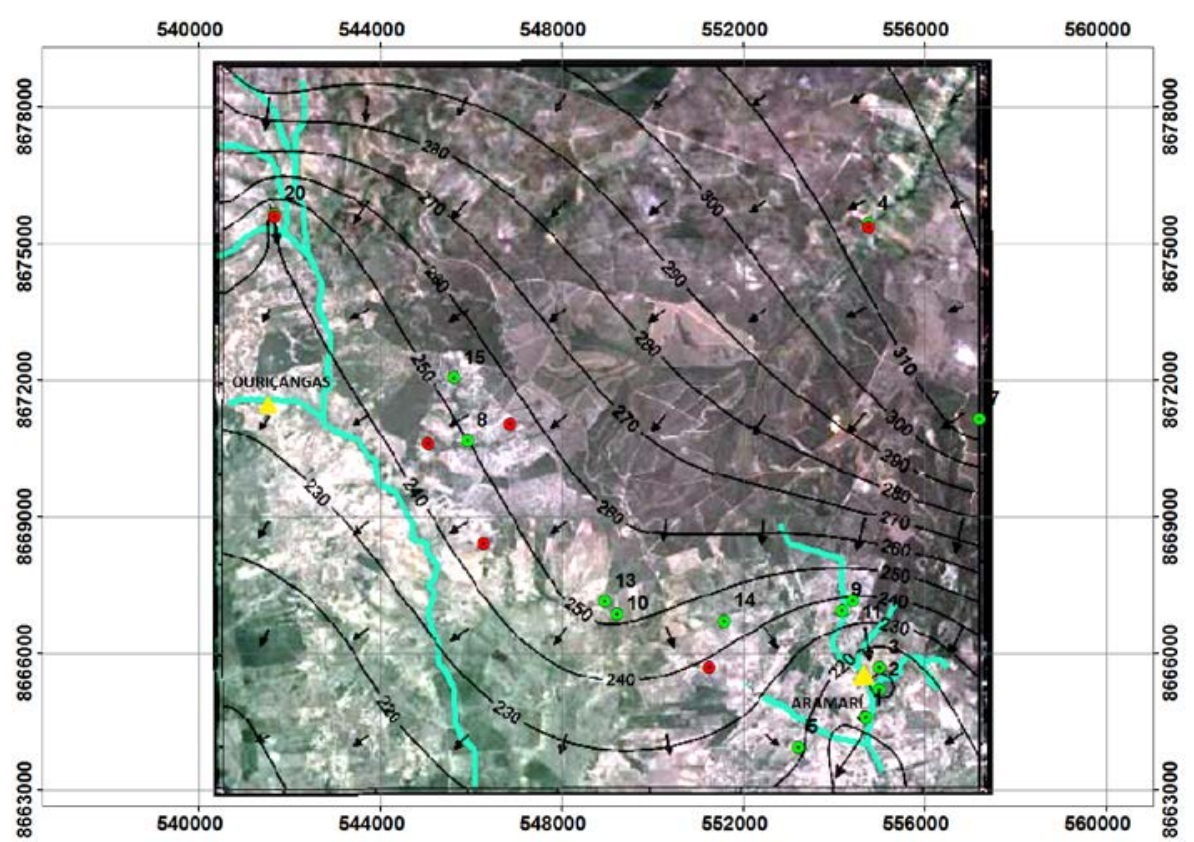

Figura 4- Mapa potenciométrico da área Figure 4- Potentiometric map of the area

O nível estático dos aqüíferos varia ao longo do ano, em função das condições de recarga, relacionado aos períodos de chuva e estiagem, e também da explotação (descarga) para fins de abastecimento urbano, comercial/industrial e irrigação. A mediana do nível potenciométrico do aquífero na região de Aramarí e Ouriçangas flutuou entre 200 e
250 metros de altitude ao longo dos últimos 40 anos. Os dados obtidos no arquivo do SIAGAS foram catalogados e organizados por década, iniciando-se por 1970 . O resultado mostrou a variação da mediana do nível da água subterrânea em relação ao nível do mar, com uma reta ascendente variando de 220 a 230 metros de altitude. (Figura 5).

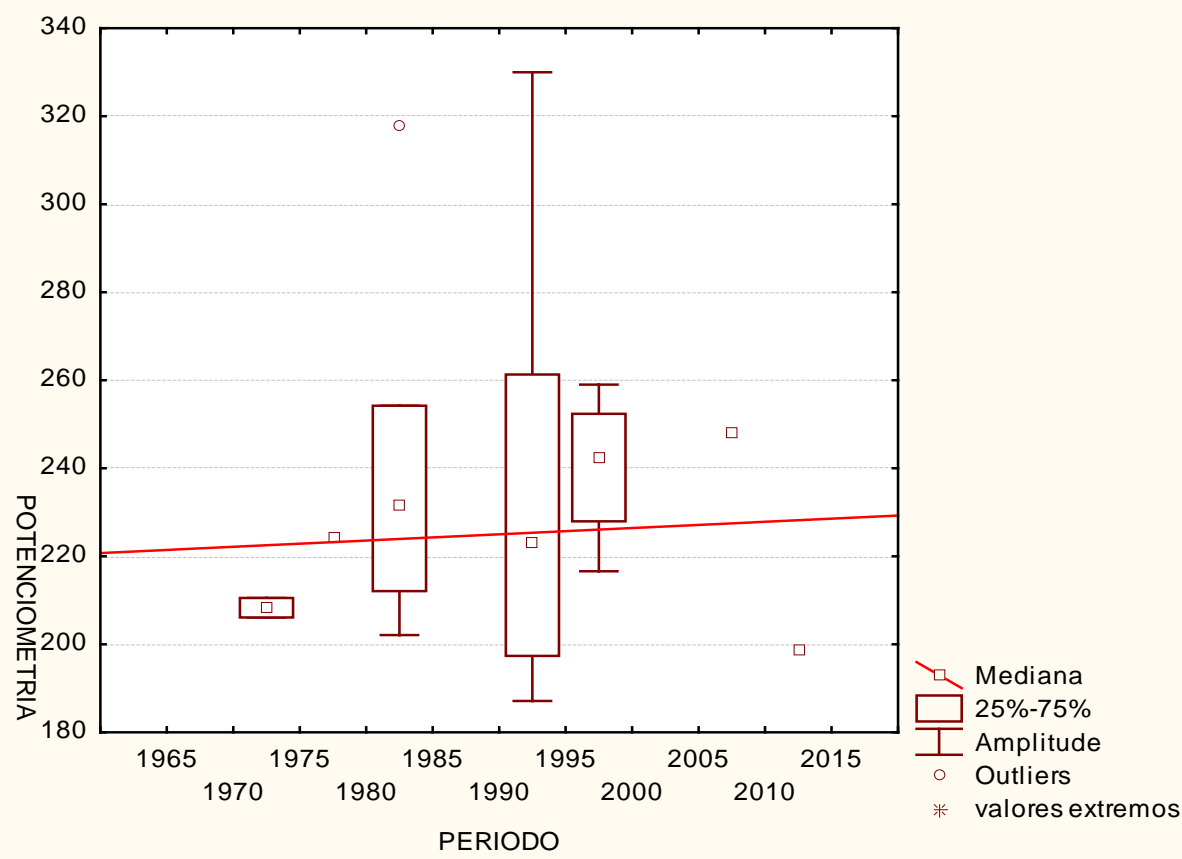

Figura 5- Posição mediana do nível potenciométrico na região de Aramarí e Ouriçangas no período de 1970 a 2014

Figure 5- Median position of the potentiometric level in the region of Aramarí and Ouriçangas in recent decades. 


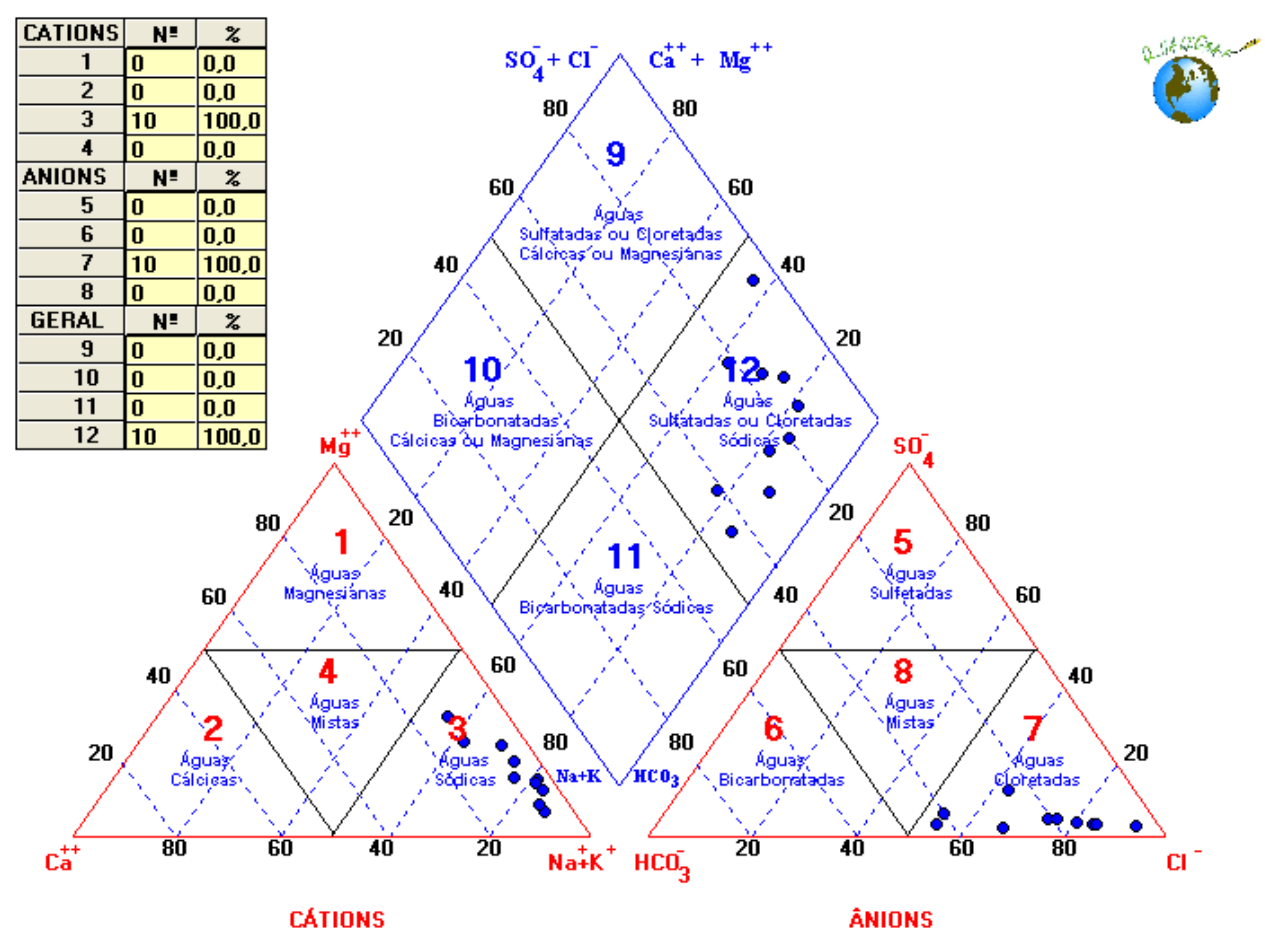

Figura 6- Diagrama Triangular de Piper

Figure 6- Triangular Diagram of Piper

A oscilação da mediana do nível de água subterrânea pode ter ocorrido devido ao fato dos poços terem sido perfurados nas últimas décadas, preferencialmente em áreas mais elevadas potenciometricamente. Dados dos 21 poços estudados mostraram que a maior amplitude de variação do nível piezométrico ocorreu entre os anos de 1990-95 (Figura 5).

\subsection{Classificação e qualidade da água sub- terrânea}

Os resultados analíticos das amostras de água coletadas de 11 poços tubulares foram plotados no diagrama triangular de PIPER (FUNCEME, 2009), e indicam que as amostras são classificadas como cloretadas sódicas (Figura 6). Com essas características, pode-se atribuir uma origem meteórica para essas águas com recarga direta a partir da circulação atmosférica oriunda principalmente do oceano Atlântico.

Qualidade da água subterrânea - A qualidade da água subterrânea pode ser considerada doce e potável dentro dos limites estabelecidos pela Portaria MS 2914/2011, com exceção dos poços P-05, P-07 e P-10 que apre- sentaram valores de $\mathrm{N}-\mathrm{NO}_{3}{ }^{-}$superiores ao limite máximo recomendado pela referida Portaria. No P-01, a salinidade expressa pelos valores de sólidos totais dissolvidos (TDS) e condutividade elétrica (CE) indica água salobra (Tabela 2). No P-02 as concentrações de chumbo e de alumínio 0,011 e 1,97 mg.L ${ }^{-1}$ respectivamente estavam acima do limite máximo recomendado, e o poço P-09 tinha 0,99 mg. $\mathrm{L}^{-1}$ de bário, portanto acima do valor máximo recomendável (Tabela 2). O poço P-09, tem uma profundidade de 69,5 metros, está situado na localidade de Baixinha/Estacada, município de Ouriçangas. A captação de água é feita no intervalo de 28 a 59 metros num nível de arenito esbranquiçado, fino à médio, subarredondado e friável da Formação Marizal (SIAGAS, 2014). O alumínio variou de 0,05 a 1,97 mg. $\mathrm{L}^{-1}$ na região (Tabela 3 ). Do ponto de vista estatístico, a salinidade da água expressa em TDS e CE para a região, pode ser conside-

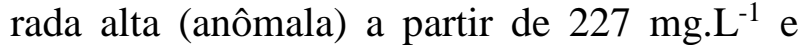
$354 \mu \mathrm{S} / \mathrm{cm}$, respectivamente (Tabela 3), embora esteja em conformidade com a Portaria MS2914/2011 para consumo humano. 
$\mathrm{O} \mathrm{NO}_{3}{ }^{-}-\mathrm{N}$ apresentou mediana de 6,50 $\mathrm{mgL}^{-1}$ com valores de 0,20 e 15,9 mg.L ${ }^{-1}$ (Tabela 3), enquanto o TDS mediana de 104,4 mg. $\mathrm{L}^{-1}$ com valores de 31,2 a $765,5 \mathrm{mg} . \mathrm{L}^{-1}$ e a CE, mediana de $163,2 \mu \mathrm{S} / \mathrm{cm}$, com valores entre 48,7 e 1196,0 $\mu \mathrm{S} / \mathrm{cm}$. Na região, os mais altos valores são dos aquíferos situados na Formação Candeias/Sergi (Poços 16 e 17) que ocorrem no sudoeste da área estudada.

Tabela 2 -Concentração de parâmetros físicos e químicos (mg. $\left.\mathrm{L}^{-1}\right)$

Table 2- Physical and chemical parameters (mg. $\mathrm{L}^{-1}$ )

\begin{tabular}{|c|c|c|c|c|c|c|c|c|c|c|c|c|}
\hline $\begin{array}{c}\text { Variável } \\
\text { versus } \\
\text { Poços } \\
\end{array}$ & Unidades & P-01 & P-02 & P-03 & P-04 & P-05 & P-06 & P-07 & P-08 & P-09 & P-10 & P-11 \\
\hline Eh & Volt & 74,0 & 119 & 129 & 57,0 & 343 & 83,0 & 75,0 & 136,0 & 91,0 & 139 & 170,0 \\
\hline OD & mg.L ${ }^{-1}$ & 7,9 & 6,26 & 7,57 & 9,9 & 6,47 & 6,59 & 6,65 & 5,93 & 6,99 & 7,83 & 6,68 \\
\hline $\mathbf{N H}_{4}$ & mg.L $\mathbf{L}^{-1}$ & $\mathbf{0 , 1}$ & 0 & 0 & 0 & 0,3 & 0,7 & 0,2 & 1,1 & 0,7 & 0 & 0,3 \\
\hline $\mathrm{NO}_{3}$ & mg.L $\mathbf{L}^{-1}$ & 8,8 & 0,8 & 9,1 & 1,0 & 15,9 & 0,2 & 15,7 & 6,5 & 0,7 & 10,9 & 5,0 \\
\hline DO & $\%$ & 99,2 & 80,3 & 96,6 & 137,9 & 84,1 & 83,5 & 83,6 & 77,2 & 90,7 & 98,7 & 83,2 \\
\hline $\mathrm{NH}_{3}$ & mg.L ${ }^{-1}$ & 0,1 & 0 & 0 & 0 & 0,3 & 0,6 & 0,2 & 1,0 & 0,6 & 0 & 0,3 \\
\hline TDS & mg.L.' & 111,3 & 104,4 & 79,6 & 32,6 & 765,5 & 65,8 & 31,2 & 173,5 & 226,8 & 54,3 & 137,5 \\
\hline $\mathbf{T}$ & ${ }^{0} \mathrm{C}$ & 26,9 & 27,5 & 27,91 & 27,44 & 28,83 & 27,54 & 27,0 & 29,03 & 28,8 & 27,22 & 26,5 \\
\hline pH & -- & 6,2 & 6,7 & 5,1 & 5,6 & 8,3 & 5,7 & 5,5 & 5,5 & 6,3 & 4,8 & 4,1 \\
\hline Sal & g.L ${ }^{-1}$ & 0,08 & 0,08 & 0,06 & 0,03 & 0,59 & 0,05 & 0,02 & 0,13 & $\mathbf{0 , 1 7}$ & 0,04 & 0,1 \\
\hline $\mathrm{Na}$ & mg.L ${ }^{-1}$ & 20,4 & 20,9 & 16,9 & 7,0 & 167,5 & 14,3 & 7,4 & 23,4 & 37 & 14,2 & --- \\
\hline $\mathbf{K}$ & mg.L ${ }^{-1}$ & 3,6 & 1,1 & 1,9 & 0,36 & 4,7 & 6,6 & 2,8 & 10,1 & 13,7 & 0,5 & ---- \\
\hline $\mathrm{Ca}$ & mg. $L^{-1}$ & 0,57 & 1,08 & 1,05 & 0,22 & 8,75 & 1,3 & 0,49 & 5,13 & 7,1 & 0,38 & ----- \\
\hline Mg & mg.L ${ }^{-1}$ & 2,0 & 2,84 & 3,07 & 0,58 & 5,04 & 1,76 & 0,37 & 8,48 & 9,24 & 0,96 & ----- \\
\hline $\mathrm{HCO}_{3}$ & mg.L $\mathbf{L}^{-1}$ & 2,5 & 2,5 & 2,5 & 2,5 & 41,5 & 6,4 & 2,5 & 4,5 & 9,6 & 2,5 & --- \\
\hline CE & $\mu \mathrm{S} / \mathrm{cm}$ & 174,0 & 163,2 & 124,4 & 50,9 & 1196 & 102,9 & 48,7 & 271,1 & 354,4 & 84,8 & 214,8 \\
\hline Ba & mg.L $\mathbf{L}^{-1}$ & $\mathbf{0 , 1 0}$ & 0,027 & 0,046 & 0,02 & 0,064 & 0,039 & 0,025 & 0,427 & 0,99 & 0,281 & 0,067 \\
\hline Zn & mg.L -1 $^{-1}$ & 0,13 & 0,2 & 0,13 & 0,14 & 0,05 & 0,06 & 0,09 & 0,05 & 0,05 & 0,12 & 0,08 \\
\hline $\mathbf{P b}$ & mg.L ${ }^{-1}$ & 0,009 & 0,011 & 0,009 & 0,009 & 0,009 & 0,009 & 0,009 & 0,009 & 0,009 & 0,009 & 0,009 \\
\hline Si & mg.L ${ }^{-1}$ & 7,0 & 4,38 & 5,3 & 5,31 & 5,12 & 18,4 & 11,4 & 10,4 & 14,6 & 5,07 & 5,17 \\
\hline $\mathbf{C u}$ & mg.L $\mathbf{L}^{-1}$ & 0,004 & 0,191 & 0,008 & 0,004 & 0,004 & 0,004 & 0,004 & 0,008 & 0,004 & 0,006 & 0,009 \\
\hline Al & mg. $\mathbf{L}^{-1}$ & 0,05 & $\mathbf{1 , 9 7}$ & 0,05 & 0,05 & 0,05 & 0,05 & 0,15 & 0,05 & 0,05 & 0,05 & 0,19 \\
\hline
\end{tabular}

Quando se analisa os valores do coeficiente $\rho$ na matriz de correlação de Spearman, verifica-se que a salinidade expressa pelo TDS esta associada ao $\mathrm{Na}^{+}(\rho=0,98)$, e $\mathrm{Cl}^{-}(\rho=0,97)$. $\mathrm{Mg}^{2+}(\rho=0,92), \mathrm{Ca}^{2+}(\rho=0,85)$ e $\mathrm{K}^{+}(\rho=0,66)$. O $\mathrm{NH}_{4}-\mathrm{N}$ e $\mathrm{NH}_{3}{ }^{-}-\mathrm{N}$ estão correlacionados ao $\mathrm{K}^{+}$ $(\rho=0,93), \mathrm{HCO}_{3}{ }^{-}(\rho=0,79)$ e o $\mathrm{Ca}^{2+}(\rho=0,71)$. O bário está associado ao $\mathrm{Mg}^{++}(\rho=0,71), \mathrm{Cl}^{-}$ $(\rho=0,65)$ e $\mathrm{Na}^{+}(\rho=0,64)$, e o $\mathrm{Pb}^{++}$ao $\mathrm{Al}^{+++}$ $(\rho=0,64)$ (Tabela 4$)$.

Foi utilizada a correlação de Spearman $(\rho)$, pelos altos valores de assimetria apresen- tados

por quase todos os parâmetros que se encontram acima do limite crítico $\left(S_{3}>0,711\right)$, com exceção do $\mathrm{NO}_{3}{ }^{-}$e $\mathrm{SO}_{4}{ }^{2-}$ e da temperatura (Tabela 3). Esse método não paramétrico não leva em conta valores extremos (muito alto ou muito baixo) que causam a assimetria. Para um nível de significância de $95 \%$ e $\mathrm{n}=11$ observações, os valores que estão acima de 0,553 apresentam correlações significativas, mas as melhores correlações são aquelas que mais se aproximam de $\pm 1,0$. 
Tabela 3-Sumário estatístico - parâmetros físicos e químicos

Table 3-Statistical Summary - physical and chemical parameters

\begin{tabular}{|c|c|c|c|c|c|c|c|c|c|c|c|c|}
\hline Variável & $\mathrm{N}$ & Média & $\begin{array}{l}\text { I.C. } \\
-95 \% \\
\end{array}$ & $\begin{array}{c}\text { I.C } \\
.+95 \% \\
\end{array}$ & Mediana & $\begin{array}{c}\text { Valor } \\
\text { Mínimo }\end{array}$ & $\begin{array}{c}\text { Valor } \\
\text { Máximo }\end{array}$ & $\begin{array}{c}\text { Quartil } \\
25 \%\end{array}$ & $\begin{array}{c}\text { Quartil } \\
75 \%\end{array}$ & $\begin{array}{c}\text { Percentil } \\
10 \%\end{array}$ & $\begin{array}{c}\text { Percentil } \\
90 \%\end{array}$ & $\mathrm{~A}_{3}$ \\
\hline Eh & 11 & 66,36 & $-27,75$ & 160,48 & 91,00 & $-343,00$ & 170,00 & 74,00 & 136,00 & 57,000 & 139,00 & $-2,95$ \\
\hline OD & 11 & 7,16 & 6,42 & 7,91 & 6,68 & 5,93 & 9,90 & 6,47 & 7,83 & 6,260 & 7,91 & 1,60 \\
\hline $\mathbf{N H}_{4}$ & 11 & 0,31 & 0,06 & 0,56 & 0,20 & 0,00 & 1,10 & 0,00 & 0,70 & 0,000 & 0,70 & 1,17 \\
\hline $\mathrm{NO}_{3}$ & 11 & 6,78 & 2,85 & 10,71 & 6,50 & 0,20 & 15,90 & 0,80 & 10,90 & 0,700 & 15,70 & 0,39 \\
\hline DO \% & 11 & 92,27 & 80,90 & 103,64 & 84,10 & 77,20 & 137,90 & 83,20 & 98,70 & 80,300 & 99,20 & 2,22 \\
\hline $\mathbf{N H}_{3}$ & 11 & 0,28 & 0,06 & 0,50 & 0,20 & 0,00 & 1,00 & 0,00 & 0,60 & 0,000 & 0,60 & 1,17 \\
\hline TDS & 11 & 162,05 & 21,68 & 302,41 & 104,40 & 31,20 & 765,50 & 54,30 & 173,50 & 32,600 & 226,80 & 2,85 \\
\hline TEMP & 11 & 27,71 & 27,15 & 28,28 & 27,53 & 26,50 & 29,03 & 27,07 & 28,83 & 26,950 & 28,83 & 0,49 \\
\hline pH & 11 & 5,80 & 5,06 & 6,54 & 5,60 & 4,10 & 8,30 & 5,10 & 6,30 & 4,800 & 6,70 & 0,94 \\
\hline Sal & 11 & 0,12 & 0,01 & 0,23 & 0,08 & 0,02 & 0,59 & 0,04 & 0,13 & 0,030 & 0,17 & 2,88 \\
\hline $\mathrm{Na}$ & 10 & 32,91 & $-1,49$ & 67,30 & 18,65 & 6,98 & 167,52 & 14,20 & 23,40 & 7,178 & 102,27 & 2,98 \\
\hline $\mathbf{K}$ & 10 & 4,53 & 1,37 & 7,69 & 3,20 & 0,36 & 13,66 & 1,08 & 6,57 & 0,421 & 11,89 & 1,20 \\
\hline Ca & 10 & 2,61 & 0,35 & 4,87 & 1,07 & 0,23 & 8,75 & 0,49 & 5,14 & 0,307 & 7,93 & 1,26 \\
\hline Mg & 10 & 3,44 & 1,17 & 5,71 & 2,43 & 0,37 & 9,24 & 0,97 & 5,04 & 0,479 & 8,86 & 1,10 \\
\hline Cl & 11 & 60,52 & 3,61 & 117,43 & 30,10 & 7,92 & 295,00 & 14,80 & 72,80 & 11,600 & 123,00 & 2,53 \\
\hline $\mathrm{HCO}_{3}$ & 10 & 26,88 & $-18,03$ & 71,79 & 3,40 & 2,50 & 204,00 & 2,50 & 13,70 & 2,500 & 116,30 & 3,06 \\
\hline $\mathrm{SO}_{4}$ & 11 & 1,65 & 0,95 & 2,35 & 1,55 & 0,34 & 3,61 & 0,81 & 2,63 & 0,750 & 2,82 & 0,63 \\
\hline CE & 11 & 253,20 & 33,90 & 472,50 & 163,20 & 48,70 & 1196,00 & 84,80 & 271,10 & 50,900 & 354,40 & 2,85 \\
\hline Ba & 11 & 0,19 & $-0,01$ & 0,39 & 0,06 & 0,02 & 0,99 & 0,03 & 0,28 & 0,025 & 0,43 & 2,39 \\
\hline Zn & 11 & 0,10 & 0,07 & 0,13 & 0,09 & 0,05 & 0,20 & 0,05 & 0,13 & 0,050 & 0,14 & 0,73 \\
\hline $\mathbf{P b}$ & 11 & 0,01 & 0,01 & 0,01 & 0,01 & 0,01 & 0,01 & 0,01 & 0,01 & 0,009 & 0,01 & 3,32 \\
\hline Si & 11 & 8,38 & 5,22 & 11,54 & 5,31 & 4,38 & 18,40 & 5,12 & 11,40 & 5,070 & 14,60 & 1,24 \\
\hline $\mathbf{C u}$ & 11 & 0,02 & $-0,02$ & 0,06 & 0,00 & 0,00 & 0,19 & 0,00 & 0,01 & 0,004 & 0,01 & 3,31 \\
\hline Al & 11 & 0,25 & $-0,14$ & 0,63 & 0,05 & 0,05 & 1,97 & 0,05 & 0,15 & 0,050 & 0,19 & 3,27 \\
\hline
\end{tabular}

Fonte: Os autores desse trabalho

$\mathrm{EH}$ = potencial redox; $\mathrm{OD}$ = oxigênio dissolvido; $\mathrm{TDS}$ = sólidos totais dissolvidos; TEMP = temperatura; $\mathrm{A}_{3}=$ Assimetria

Tabela 4- Matriz de correlação - Spearman

(continuação)

Table 4- Correlation matrix - Spearman

\begin{tabular}{|c|c|c|c|c|c|c|c|c|c|c|c|c|}
\hline Variáveis & Eh & OD & $\mathbf{N H}_{\mathbf{4}}$ & $\mathbf{N O}_{\mathbf{3}}$ & $\mathbf{D O} \%$ & $\mathbf{N H}_{\mathbf{3}}$ & $\mathbf{T D S}$ & $\mathbf{T E M P}$ & $\mathbf{p H}$ & Sal & $\mathbf{N a}$ & $\mathbf{K}$ \\
\hline Eh & 1,00 & $-0,15$ & 0,04 & $-0,14$ & $-0,42$ & 0,04 & 0,05 & $-0,10$ & $-0,70$ & 0,06 & 0,01 & $-0,02$ \\
\hline OD & $-0,15$ & 1,00 & $-0,54$ & 0,05 & 0,92 & $-0,54$ & $-0,40$ & 0,49 & $-0,28$ & $-0,44$ & $-0,58$ & $-0,50$ \\
\hline $\mathbf{N H}_{\mathbf{4}}$ & 0,04 & $-0,54$ & 1,00 & $-0,25$ & $-0,54$ & 1,00 & 0,56 & 0,43 & 0,14 & 0,55 & 0,50 & 0,93 \\
\hline $\mathbf{N O}_{3}$ & $-0,14$ & 0,05 & $-0,25$ & 1,00 & 0,22 & $-0,25$ & $-0,05$ & $-0,11$ & $-0,19$ & $-0,06$ & $-0,03$ & $-0,26$ \\
\hline $\mathbf{D O}$ & $-0,42$ & 0,92 & $-0,54$ & 0,22 & 1,00 & $-0,54$ & $-0,32$ & $-0,26$ & $-0,01$ & $-0,36$ & $-0,41$ & $-0,49$ \\
\hline $\mathbf{N H}_{3}$ & 0,04 & $-0,54$ & 1,00 & $-0,25$ & $-0,54$ & 1,00 & 0,56 & 0,43 & 0,14 & 0,55 & 0,50 & 0,93 \\
\hline TDS & 0,05 & $-0,40$ & 0,56 & $-0,05$ & $-0,32$ & 0,56 & 1,00 & 0,49 & 0,41 & 1,00 & 0,98 & 0,66 \\
\hline TEMP & $-0,10$ & $-0,49$ & 0,43 & $-0,11$ & $-0,26$ & 0,43 & 0,49 & 1,00 & 0,41 & 0,51 & 0,68 & 0,60 \\
\hline $\mathbf{p H}$ & $-0,70$ & $-0,28$ & 0,14 & $-0,19$ & $-0,01$ & 0,14 & 0,41 & 0,41 & 1,00 & 0,42 & 0,63 & 0,35 \\
\hline Sal & 0,06 & $-0,44$ & 0,55 & $-0,06$ & $-0,36$ & 0,55 & 1,00 & 0,51 & 0,42 & 1,00 & 0,98 & 0,64 \\
\hline $\mathbf{N a}$ & 0,01 & $-0,58$ & 0,50 & $-0,03$ & $-0,41$ & 0,50 & 0,98 & 0,68 & 0,63 & 0,98 & 1,00 & 0,67 \\
\hline
\end{tabular}


Tabela 4- Matriz de correlação - Spearman

(conclusão)

Table 4- Correlation matrix - Spearman

\begin{tabular}{|c|c|c|c|c|c|c|c|c|c|c|c|c|}
\hline Variáveis & Eh & OD & $\mathrm{NH}_{4}$ & $\mathrm{NO}_{3}$ & DO \% & $\mathrm{NH}_{3}$ & TDS & TEMP & pH & Sal & $\mathrm{Na}$ & $\mathbf{K}$ \\
\hline K & $-0,02$ & $-0,50$ & 0,93 & $-0,26$ & $-0,49$ & 0,93 & 0,66 & 0,60 & 0,35 & 0,64 & 0,67 & 1,00 \\
\hline Ca & $-0,04$ & $-0,71$ & 0,71 & $-0,16$ & $-0,59$ & 0,71 & 0,85 & 0,80 & 0,60 & 0,87 & 0,90 & 0,82 \\
\hline Mg & 0,21 & $-0,47$ & 0,48 & $-0,19$ & $-0,33$ & 0,48 & 0,92 & 0,82 & 0,40 & 0,92 & 0,92 & 0,67 \\
\hline Cl & 0,15 & $-0,48$ & 0,48 & 0,03 & $-0,40$ & 0,48 & 0,97 & 0,51 & 0,34 & 0,98 & 0,96 & 0,54 \\
\hline $\mathrm{HCO}_{3}$ & $-0,34$ & $-0,48$ & 0,79 & 0,01 & $-0,42$ & 0,79 & 0,45 & 0,53 & 0,45 & 0,45 & 0,50 & 0,76 \\
\hline $\mathrm{SO}_{4}$ & $-0,11$ & 0,00 & 0,42 & $-0,32$ & $-0,05$ & 0,42 & 0,51 & 0,44 & 0,21 & 0,51 & 0,38 & 0,37 \\
\hline $\mathrm{CE}$ & 0,05 & $-0,40$ & 0,56 & $-0,05$ & $-0,32$ & 0,56 & 1,00 & 0,49 & 0,41 & 1,00 & 0,98 & 0,66 \\
\hline Ba & 0,44 & $-0,05$ & 0,48 & 0,01 & $-0,07$ & 0,48 & 0,65 & 0,29 & $-0,08$ & 0,63 & 0,64 & 0,61 \\
\hline Zn & $-0,04$ & 0,46 & $-0,90$ & $-0,05$ & 0,38 & $-0,90$ & $-0,60$ & $-0,52$ & $-0,09$ & $-0,59$ & $-0,53$ & $-0,83$ \\
\hline $\mathbf{P b}$ & 0,10 & $-0,40$ & $-0,36$ & $-0,30$ & $-0,40$ & $-0,36$ & 0,00 & 0,00 & 0,40 & 0,05 & 0,17 & 0,29 \\
\hline Si & $-0,24$ & 0,00 & 0,64 & $-0,36$ & $-0,03$ & 0,64 & $-0,07$ & 0,20 & 0,05 & $-0,10$ & $-0,07$ & 0,67 \\
\hline $\mathrm{Cu}$ & 0,79 & $-0,34$ & $-0,22$ & $-0,08$ & $-0,54$ & $-0,22$ & 0,12 & $-0,04$ & $-0,39$ & 0,16 & 0,15 & $-0,25$ \\
\hline Al & 0,29 & $-0,35$ & $-0,17$ & $-0,08$ & $-0,54$ & $-0,17$ & $-0,13$ & $-0,48$ & $-0,10$ & $-0,10$ & $-0,13$ & $-0,28$ \\
\hline Eh & $-0,04$ & 0,21 & 0,15 & $-0,34$ & $-0,11$ & 0,05 & 0,44 & $-0,04$ & 0,10 & $-0,24$ & 0,79 & 0,29 \\
\hline OD & $-0,71$ & $-0,47$ & $-0,48$ & $-0,48$ & 0,00 & $-0,40$ & $-0,05$ & 0,46 & $-0,40$ & 0,00 & $-0,34$ & $-0,35$ \\
\hline $\mathrm{NH}_{4}$ & 0,71 & 0,48 & 0,48 & 0,79 & 0,42 & 0,56 & 0,48 & $-0,90$ & $-0,36$ & 0,64 & $-0,22$ & $-0,17$ \\
\hline $\mathrm{NO}_{3}$ & $-0,16$ & $-0,19$ & 0,03 & 0,01 & $-0,32$ & $-0,05$ & 0,01 & $-0,05$ & $-0,30$ & $-0,36$ & $-0,08$ & $-0,08$ \\
\hline DO $\%$ & $-0,59$ & $-0,33$ & $-0,40$ & $-0,42$ & 0,05 & $-0,32$ & $-0,07$ & 0,38 & $-0,40$ & $-0,03$ & $-0,54$ & $-0,54$ \\
\hline $\mathbf{N H}_{3}$ & 0,71 & 0,48 & 0,48 & 0,79 & 0,42 & 0,56 & 0,48 & $-0,90$ & $-0,36$ & 0,64 & $-0,22$ & $-0,17$ \\
\hline TDS & 0,85 & 0,92 & 0,97 & 0,45 & 0,51 & 1,00 & 0,65 & $-0,60$ & 0,00 & $-0,07$ & 0,12 & $-0,13$ \\
\hline TEMP & 0,80 & 0,82 & 0,51 & 0,53 & 0,44 & 0,49 & 0,29 & $-0,52$ & 0,00 & 0,20 & $-0,04$ & $-0,48$ \\
\hline pH & 0,60 & 0,40 & 0,34 & 0,45 & 0,21 & 0,41 & $-0,08$ & $-0,09$ & 0,40 & 0,05 & $-0,39$ & $-0,10$ \\
\hline Sal & 0,87 & 0,92 & 0,98 & 0,45 & 0,51 & 1,00 & 0,63 & $-0,59$ & 0,05 & $-0,10$ & 0,16 & $-0,10$ \\
\hline $\mathrm{Na}$ & 0,90 & 0,92 & 0,96 & 0,50 & 0,38 & 0,98 & 0,64 & $-0,53$ & 0,17 & $-0,07$ & 0,15 & $-0,13$ \\
\hline $\mathbf{K}$ & 0,82 & 0,67 & 0,54 & 0,76 & 0,37 & 0,66 & 0,61 & $-0,83$ & $-0,29$ & 0,67 & $-0,25$ & $-0,28$ \\
\hline $\mathrm{Ca}$ & 1,00 & 0,84 & 0,81 & 0,74 & 0,50 & 0,85 & 0,50 & $-0,70$ & 0,06 & 0,21 & 0,01 & $-0,15$ \\
\hline Mg & 0,84 & 1,00 & 0,90 & 0,38 & 0,48 & 0,92 & 0,71 & $-0,51$ & 0,06 & 0,03 & 0,27 & $-0,30$ \\
\hline Cl & 0,81 & 0,90 & 1,00 & 0,34 & 0,45 & 0,97 & 0,65 & $-0,55$ & 0,10 & $-0,23$ & 0,28 & $-0,06$ \\
\hline $\mathrm{HCO}_{3}$ & 0,74 & 0,38 & 0,34 & 1,00 & 0,55 & 0,45 & 0,25 & $-0,86$ & $-0,31$ & 0,52 & $-0,51$ & $-0,13$ \\
\hline $\mathrm{SO}_{4}$ & 0,50 & 0,48 & 0,45 & 0,55 & 1,00 & 0,51 & 0,27 & $-0,54$ & $-0,30$ & 0,10 & $-0,23$ & $-0,36$ \\
\hline $\mathrm{CE}$ & 0,85 & 0,92 & 0,97 & 0,45 & 0,51 & 1,00 & 0,65 & $-0,60$ & 0,00 & $-0,07$ & 0,12 & $-0,13$ \\
\hline $\mathbf{B a}$ & 0,50 & 0,71 & 0,65 & 0,25 & 0,27 & 0,65 & 1,00 & $-0,57$ & $-0,30$ & 0,09 & 0,09 & $-0,37$ \\
\hline $\mathrm{Zn}$ & $-0,70$ & $-0,51$ & $-0,55$ & $-0,86$ & $-0,54$ & $-0,60$ & $-0,57$ & 1,00 & 0,51 & $-0,45$ & 0,27 & 0,32 \\
\hline $\mathbf{P b}$ & 0,06 & 0,06 & 0,10 & $-0,31$ & $-0,30$ & 0,00 & $-0,30$ & 0,51 & 1,00 & $-0,50$ & 0,55 & 0,64 \\
\hline Si & 0,21 & 0,03 & $-0,23$ & 0,52 & 0,10 & $-0,07$ & 0,09 & $-0,45$ & $-0,50$ & 1,00 & $-0,59$ & $-0,35$ \\
\hline $\mathrm{Cu}$ & 0,01 & 0,27 & 0,28 & $-0,51$ & $-0,23$ & 0,12 & 0,09 & 0,27 & 0,55 & $-0,59$ & 1,00 & 0,55 \\
\hline Al & $-0,15$ & $-0,30$ & $-0,06$ & $-0,13$ & $-0,36$ & $-0,13$ & $-0,37$ & 0,32 & 0,64 & $-0,35$ & 0,55 & 1,00 \\
\hline
\end{tabular}

\subsection{Modelamento Geoquímico}

Para a obtenção do índice de saturação (I.S.) e da especiação do elemento bário, foi utilizado o aplicativo PHREEQC 2.0, (Parkhurst \& Appelo, 1999). Os resultados

positivos representam a supersaturação de um determinado elemento na água em relação a fase sólida (mineral), e os negativos representam solução subsaturada nesse elemento. 
Quando o I.S. é igual a zero a solução está em equilíbrio químico. O valor do I.S. é obtido pela relação entre o Produto da Atividade Iônica (IAP) dos elementos pela constante de equilíbrio termodinâmica $(\mathrm{K})$ na temperatura (T) da reação considerada, ou seja: I.S. = IAP / $\mathrm{K}_{\mathrm{T}}$. Como os valores do IAP variam em ordem de grandeza é conveniente utilizar a equação em valores logarítmicos, ou seja: log I.S. $=\log \mathrm{IAP}-\log \mathrm{KT}$.

Os cálculos efetuados com os dados da região de Aramarí mostraram que a água subterrânea apresenta-se saturada em bário apenas no poço P-09 (Tabela 5). Esse elemento estaria na água desse ponto essencialmente sob a forma de $\mathrm{Ba}^{+2}(98,9 \%)$ e, secundariamente, sob a forma de $\mathrm{BaSO}_{4}(1,04 \%)$. As espécies carbonáticas encontram-se em quantidades desprezíveis (Tabela 5). Nessa tabela os valores da especiação estão representados por um percentual do total da molalidade da solução. Os índices de saturação são apresentados em valores logarítmicos.

Tabela 5 - Índice de saturação (I.S.) e especiação do bário (\%) na água subterrânea

Table 5 - Saturation index (S.I.) and speciation of barium (\%) in groundwater

\begin{tabular}{c|l|l|l|l|l|l|l|l|l|l}
\hline & P-01 & $\mathbf{P - 0 2}$ & $\mathbf{P - 0 3}$ & $\mathbf{P - 0 4}$ & $\mathbf{P - 0 5}$ & $\mathbf{P - 0 6}$ & $\mathbf{P - 0 7}$ & $\mathbf{P - 0 8}$ & $\mathbf{P - 0 9}$ & $\mathbf{P - 1 0}$ \\
\hline I.S. & $-1,45$ & $-2,0$ & $-1,78$ & $-1,56$ & $-1,33$ & $-1,52$ & $-2,38$ & $-0,65$ & $\mathbf{0 , 0 9}$ & $-0,89$ \\
\hline Ba $^{+2}$ & 99,71 & 99,69 & 99,70 & 98,90 & 99,20 & 99,36 & 99,89 & 99,55 & & 99,70 \\
& & & & & & & & & 98,90 & \\
\hline BaSO $^{4}$ & 0,27 & 0,30 & 0,30 & 1,10 & 0,62 & 0,62 & 0,13 & 0,44 & 1,04 & 0,30 \\
\hline BaHCO $^{3+}$ & 0,02 & 0,03 & 0,00 & 0,01 & 0,13 & 0,01 & 0,00 & 0,05 & 0,02 & 0,00 \\
\hline BaCO $^{3}+\mathbf{B a O H}$ & 0,00 & ------ & 0,00 & ------ & 0,05 & 0,01 & ------ & ------ & 0,04 & ------- \\
& & & & & & & & - & & \\
\hline Total & 100,0 & 100,0 & 100,0 & 100,0 & 100,0 & 100,0 & 100,0 & 100,0 & 100,0 & 100,0 \\
\hline
\end{tabular}

Em nove dos 10 poços estudados o I.S. foi negativo, indicando que as águas subterrâneas estão insaturadas com o bário e, consequentemente, não existe a possibilidade de precipitação de qualquer composto desse elemento nesses poços (Tabela 5). Convém assinalar que mesmo na água saturada do poço 09 em que ocorre precipitação alguma barita (1,04\%), ocorre $\mathrm{Ba}^{++}$dissolvido em grande quantidade (98,90\%). A possibilidade de precipitação do bário sob a forma de $\mathrm{BaCO}_{3}$ (Witerita) na região é muito pequena já que os índices de saturação apresentados foram sempre negativos em todos os poços estudados, como mostra a Figura 8.

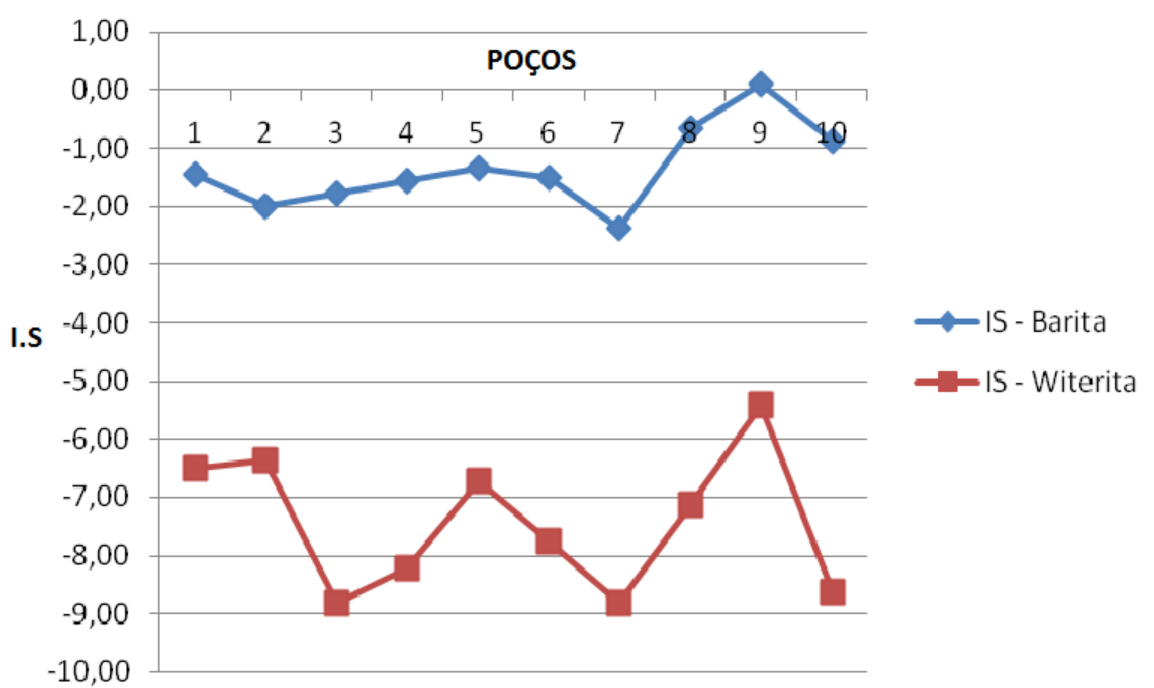

Figura 8- Índice de Saturação (IS) da barita e da witerita nos pontos de amostragem.

Figure 8- Variation of the saturation index (SI) at the sampling points. 


\section{CONCLUSÕES}

$\mathrm{Na}$ região de Aramarí e Ouriçangas os guns poços, o $\mathrm{N}-\mathrm{NO}^{3}$, o potássio, o bário, o aquíferos apresentam vazão mediana de 13,9 chumbo e o alumínio não apresentam conformi$\mathrm{m}^{3} / \mathrm{h}$, nos 21 poços estudados. Estatisticamente, dade com os valores máximos permitidos pela os poços com vazões acima de $34,9 \mathrm{~m}^{3} / \mathrm{h}$ podem Portaria MS 2917/2011. A alta concentração de ser considerados como excepcionais. A vazão alumínio pode ser atribuída, provavelmente, a específica mediana nos 21 poços estudados foi algum problema com a filtração da água no camde $0,5 \mathrm{~m}^{3} / \mathrm{h} / \mathrm{m}$ e os poços com vazões específicas po. O N-NO ${ }^{3}$ poderá estar ligado a contaminaacima de $2,0 \mathrm{~m}^{3} / \mathrm{h} / \mathrm{m}$ podem ser considerados ções por esgotos domésticos e urbanos e atividacomo excepcionais na região. Os poços tubulares de de origem rural. A salinidade das águas exestudados que apresentam boa produção e alta pressa pelo TDS em 21 poços tubulares são devazão específica produzem água originada das vidos principalmente aos íons $\mathrm{Na}^{+}, \mathrm{K}^{+}, \mathrm{Ca}^{++}$, Formações Barreiras Marizal, São Sebastião e do $\mathrm{Mg}^{++}, \mathrm{Cl}^{-}$e $\mathrm{Ba}^{++}$.

Grupo Ilhas.

O fluxo subterrâneo regional nos municípios de Aramarí e Ouriçangas apresenta um sentido aproximado NE-SW. Os valores medianos da superfície piezométrica variaram entre 200 e 250 metros de altitude em relação ao nível do mar nas últimas quatro décadas (1970 a 2010), talvez em função das recargas terem sido maiores do que as descargas e/ou a existência de uma quantidade maior de poços perfurados em áreas com superfícies piezométricas mais altas nas últimas décadas;

As águas subterrâneas da região apresentaram-se cloretadas-sódicas em 11 poços tubulares, associando-se provavelmente a uma origem a partir das águas meteóricas influenciadas pela circulação atmosféricas vindas do mar. As águas subterrâneas são de um modo geral de boa qualidade, com exceção dos poços P-05 e os poços 16 e 17 que apresentaram altas salinidades devido a influencia da Formação Candeias/Sergi. Em al-

\section{REFERÊNCIAS}

BRASIL. MINISTÉRIO DAS MINAS E ENERGIA. Secretaria geral. Projeto RADAMBRASIL. Folha SD24. Salvador; geologia, geomorfologia, pedologia, vegetação e uso potencial da terra. Rio de Janeiro, 1981.

BRASIL. MINISTÉRIO DA SAÚDE. Portaria $\mathbf{n}^{\mathbf{0}}$ 2.914, de 12 de dezembro de 2011. Dispõe sobre os procedimentos de controle e de vigilância da qualidade da água para consumo humano e seu padrão de potabilidade. Disponível

em:

<http://www.in.gov.br/visualiza/index.jsp?data=14/12/2

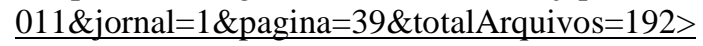

COMPANHIA BAIANA DE PESQUISA MINERAL CBPM. Projeto Aramarí: geologia e potencialida-
A correlação hidrogeoquímica do bário com o chumbo é, provavelmente, consequência da presença desse elemento nas diversas litologias da área, principalmente em alguns folhelhos do Grupo Ilhas.

O maior valor do Índice de saturação para bário foi encontrado no poço P-09 perfurado na Formação Marizal. Nesse local as condições de pH $(6,3)$ e Eh oxidante são favoráveis a precipitação do bário sob a forma de barita, embora a disponibilidade de $\mathrm{SO}^{4}$ seja pequena na água. A baixa correlação entre ambos na água $(\rho=0,27)$ atesta a fraca afinidade entre eles. Devido a isso, o bário está preferencialmente sob a forma de $\mathrm{Ba}^{++}(98,9 \%)$ e, secundariamente, sob a forma de $\mathrm{BaSO}^{4}(1,04 \%)$. No caso da Witerita $\left(\mathrm{BaCO}^{3}\right)$, as condições de $\mathrm{pH}$ da água $(6,3)$, a pequena disponibilidade de $\mathrm{HCO}^{3}$ e o baixo índice de saturação inviabiliza a sua precipitação. A baixa correlação entre o $\mathrm{Ba}^{++}$e o $\mathrm{HCO}^{3-}$.na água $(\rho=0,25)$ mostra a fraca afinidade entre ambos.

de econômica. Salvador, 1984. (Relatório interno).

COMPANHIA BAIANA DE PESQUISA MINERAL CBPM. Depósitos de argila do Recôncavo Baiano: geologia e potencialidade econômica. Salvador, v.15, 2001. (Série Arquivos Abertos).

COMPANHIA DE PESQUISA E RECURSOS MINERAIS - CPRM. Projeto Cadastro de Fontes de Abastecimento por Água Subterrânea. Diagnóstico do Município de Ouriçangas - Bahia. Salvador: CPRM/PRODEEM, 2005

COSTA, W. D.; FEITOSA, F. A. C. (coords.). Hidrogeologia da bacia sedimentar do Jatobá: sistema aquífero 
Tacaratu/Inajá. In: Comportamento das Bacias Sedimentares da Região Semi-Árida do Nordeste Brasileiro. CPRM, Brasília, 2007.

FIUME, B. Hidrogeoquímica do bário em poços de abastecimento do estado de São Paulo monitorados pela Cetesb. São Paulo, 2010.

FONSECA, P. P. Mapeamento geológico e zoneamento geoambiental da região do pólo industrial de Camaçari, através do uso de ortofotos digitais. Salvador: UFBA, 2004.

FUNCEME - Fundação Cearense de Meteorologia e Recursos Hídricos. Guia do Usuário para Qualigraf. FUNCEME/PROURB-RH. Fortaleza-Ceará, 2009.

INSTITUTO BRASILEIRO DE GEOGRAFIA E ESTATÍSTICA - IBGE Levantamento de recursos naturais. Volume 24 (Suplemento) Folha SD - 24 Salvador. Potencial dos Recursos Hídricos. Rio de Janeiro. 1999

INSTITUTO NACIONAL DE METEOROLOGIA INMET. Normais climatológicas do Brasil 1961-1990. Disponível em: http://www,inmet,gov,br/portal/index,php?r=clima/norma isClimatologicas>. Acesso em: 15 jan. 2014.

LIMA, O. A. L. Avaliação hidrogeofísica de arenitos aquíferos na bacia do Recôncavo-Tucano (BA). In: $2^{\circ}$ CONGRESSO INTERNACIONAL DA SOCIEDADE
BRASILEIRA DE GEOFÍSICA, 2, 1991, Salvador. Anais. Salvador: SBGf, 1991. P.1016-1022.

NUNES, F.C.; SILVA, E. F.; VILAS BOAS, G. S. Grupo Barreiras: Características, Gênese e Evidências de Neotectonismo. Boletim de Pesquisa e Desenvolvimento. Rio de Janeiro: EMBRAPA, 2011.

PARKHURST, D. L. E APPELO, C. A. J. User's guide to PHREEQC (Version 2). A computer program for speciation, batch-reaction, one-dimensional transport, and inverse geochemical calculations. U.S. Geological Survey Water-Resources Investigations, Report 99-4259, 310 pp 1999.

SISTEMA DE INFORMAÇÃO DE ÁGUAS SUBTERRÂNEAS - SIAGAS (2013). Fichas de poços tubulares. Disponível em

$<$ http://siagasweb.cprm.gov.br/layout/pesquisa_complexa. php>. Acesso em 23 de outubro de 2013.

SOUZA, W.S.T. 1984. O estudo das unidades deposicionais na pesquisa de mineralizações de stratabound; um exemplo de aplicação na formação Marizal, Bahia. $33^{\circ}$ Congresso Brasileiro de Geologia, Rio de Janeiro, RJ. Anais: Sociedade Brasileira de Geologia, p. 1106- 1109.

SUPERINTENDÊNCIA DE ESTUDOS ECONÔMICOS E SOCIAIS DA BAHIA - SEI. Análise dos atributos climáticos do estado da Bahia. Salvador, 1998. 85 p. 